\title{
Ectopic localization of FOXO3a protein in Lewy bodies in Lewy body dementia and Parkinson's disease
}

\author{
Bo Su${ }^{\dagger 1}$, Haihua Liu ${ }^{\dagger 1}$, Xinglong Wang1, Shu G Chen ${ }^{1}$, Sandra L Siedlak1, \\ Eisaku Kondo ${ }^{2}$, Raymond Choi ${ }^{1}$, Atsushi Takeda ${ }^{3}$, Rudy J Castellani ${ }^{4}$, \\ George Perry ${ }^{5}$, Mark A Smith1, Xiongwei Zhu*1 and Hyoung-gon Lee*1
}

\begin{abstract}
Address: ${ }^{1}$ Department of Pathology, Case Western Reserve University, Cleveland, Ohio 44106, USA, ${ }^{2}$ Department of Pathology, Okayama University Graduate School of Medicine and Dentistry, Okayama 700-8558, Japan, ${ }^{3}$ Department of Pathology, University of Maryland, Baltimore, Maryland 21201, USA, ${ }^{4}$ Division of Neurology, Department of Neuroscience, Tohoku University Graduate School of Medicine, Sendai, Japan and ${ }^{5}$ UTSA Neurosciences Institute and Department of Biology, College of Sciences, University of Texas at San Antonio, San Antonio, Texas 78249, USA

Email: Bo Su - bo.su@case.edu; Haihua Liu - haihau.liu@case.edu; Xinglong Wang -xinglong.wang@case.edu; Shu G Chen - shu.chen@case.edu; Sandra L Siedlak - sandra.siedlak@case.edu; Eisaku Kondo - ekondo@md.okayama-u.ac.jp; Raymond Choi - raymond.choi@case.edu; Atsushi Takeda - atakeda@em.neurol.med.tohoku.ac.jp;

Rudy J Castellani - rcastellani@som.umaryland.edu; George Perry - george.perry@utsa.edu; Mark A Smith - mark.smith@case.edu; Xiongwei Zhu* - xiongwei.zhu@case.edu; Hyoung-gon Lee* - hyoung-gon.lee@case.edu

* Corresponding authors †Equal contributors
\end{abstract}

Published: 23 July 2009

Molecular Neurodegeneration 2009, 4:32 doi:10.1186/1750-1326-4-32
Received: 4 June 2009

Accepted: 23 July 2009

This article is available from: http://www.molecularneurodegeneration.com/content/4/I/32

(c) 2009 Su et al; licensee BioMed Central Ltd.

This is an Open Access article distributed under the terms of the Creative Commons Attribution License (http://creativecommons.org/licenses/by/2.0), which permits unrestricted use, distribution, and reproduction in any medium, provided the original work is properly cited.

\begin{abstract}
Lewy bodies and Lewy neurites constitute the cardinal neuropathological features of both Parkinson's disease (PD) and Lewy body dementia (LBD). Whereas $\alpha$-synuclein has been found to be the major component of the Lewy body, the mechanisms by which neurons degenerate, as well as basic mechanisms involved in the formation of $\alpha$-synuclein-related inclusions, remain obscure. We have suggested previously that potential mechanisms are likely to leave a "molecular signature" or protein adduct within the Lewy body, and have found examples of such signatures in previous studies. In this study, we demonstrate increased $\mathrm{FOXO} 3$ in association with Lewy bodies and Lewy neurites in LBD and PD brain tissue. Since FOXO proteins are involved in several pathways responsible for the regulation of cell death, cell proliferation, and cell metabolism, the ectopic localization of $\mathrm{FOXO} 3$ to Lewy bodies provides evidence that aberrations in basic cellular biochemistry may contribute to inclusion formation, which is likely more complex than a simple "gain of function" toxicity as is commonly opined. In light of the known interaction of FOXO3 and 14-3-3, basic protein-protein interaction between these proteins and $\alpha$-synuclein may be key.
\end{abstract}

\section{Background}

Parkinson's disease (PD) is the second most common agerelated neurodegenerative disease after Alzheimer's disease (AD) $[1,2]$. Like many other neurodegenerative diseases, PD and Lewy body dementia (LBD) are increasingly recognized as disorders of protein aggregation and inclusion body formation [3]; in particular, PD is defined by the presence of Lewy bodies and Lewy neurites $[4,5]$. Cortical Lewy bodies also constitute the defining neuropathological characteristics of LBD, a common form of dementia that exists in a "pure" form or overlaps with $\mathrm{AD}$ neuropathology [4]. $\alpha$-Synuclein is the major component of the Lewy body in PD and LBD [6] and is currently used as a diagnostic marker of Lewy bodies. Mutations in $\alpha$ - 
synuclein are also described in a subset of familial PD kindreds, whereas aggregated $\alpha$-synuclein occurs in both familial and sporadic PD lesions [7]. Besides $\alpha$-synuclein, many molecules such as 14-3-3 protein and ubiquitin have been found in Lewy bodies [8-10]. It is also suggested that 14-3-3 protein which shares amino acid sequence homology with $\alpha$-synuclein may be associated with Lewy body formation [8].

It is generally accepted that progressive, irreversible and regionally specific neurodegeneration, with Lewy bodies and Lewy neurites are the essential pathological hallmarks of idiopathic PD. The precise etiology, however, is unclear. One of the leading hypotheses suggests that oxidative stress and generation of reactive oxygen species damages macromolecules, resulting ultimately in cell death [11]. In fact, Lewy bodies themselves have been shown to contain adducts induced by oxidative stress [12].

The forkhead box transcription factor, class $\mathrm{O}$ (FOXO) is the mammalian homologue of DAF-16, which is known to regulate life span of Caenorhabditis elegans $[13,14]$. In mammals, the FOXO class of transcription factors are key players in the regulation of cell-fate decisions, such as cell death, cell proliferation, and cell metabolism [15]. It has been reported that phosphorylation/dephosphorylation of FOXO protein, which results in the translocation between cytoplasm and nucleus, is a major regulatory mechanism of FOXO-dependent-transcription [16]. A recent study indicated that three FOXO family members including FOXO1, FOXO3, and FOXO4 play essential roles in the response to physiologic oxidative stress in hematopoietic stem cells of experimental mice [17]. In the present study, we examined the expression of FOXO3a (also known as FKHRL1) in brain tissue from cases of PD and LBD.

\section{Methods}

\section{Brain tissue}

Hippocampal tissue with adjacent temporal cortex from patients with "pure" LBD ( $\mathrm{n}=3$, ages 68-78 years), LBD plus $\mathrm{AD}$ pathology $(\mathrm{AD} / \mathrm{LBD})(\mathrm{n}=4$, ages $59-84$ years $)$, brainstem from PD cases ( $\mathrm{n}=4$, ages 53-108 years), and age-matched controls ( $\mathrm{n}=3$, ages $66-86$ years) with similar postmortem intervals (LBD, AD/LBD and PD: 4-15 h; controls: $6.25-22 \mathrm{~h}$ ), were fixed either in formalin or in methacarn (methanol:chloroform:acetic acid; 60:30:10) at $4{ }^{\circ} \mathrm{C}$ overnight. Following fixation, tissue was dehydrated through ascending ethanol, embedded in paraffin, and $6-\mu \mathrm{m}$ sections placed on silane-coated slides.

\section{Immunohistochemistry}

Immunohistochemistry was performed by the peroxidase anti-peroxidase protocol essentially as described previ- ously $[18,19]$. All slides were randomized and blinded with regards to age and disease status prior to immunohistochemical staining and subsequent analysis. Briefly, slides were immersed in xylene, hydrated through graded ethanol solutions, and endogenous peroxidase activity eliminated by incubation in 3\% hydrogen peroxide for 30 min. To reduce non-specific binding, sections were incubated for $30 \mathrm{~min}$ in 10\% normal goat serum in Tris-buffered saline (TBS; $50 \mathrm{mM}$ Tris- $\mathrm{HCl}, 150 \mathrm{mM} \mathrm{NaCl}, \mathrm{pH}$ 7.6). After rinsing briefly with $1 \%$ normal goat serum in TBS, the sections were incubated overnight at $4{ }^{\circ} \mathrm{C}$ with either rabbit polyclonal antibody to FKHRL1 (FOXO3a) $(1: 100)[20]$, mouse monoclonal antibody to $\alpha$-synuclein (1:100; Abcam, Cambridge, MA) or rabbit polyclonal antibody to 14-3-3 $\beta$ (1:100; Santa Cruz Biotechnology, Santa Cruz, CA). Sections were sequentially thereafter incubated with either goat anti-rabbit or goat anti-mouse antisera (ICN, Costa Mesa, CA) followed by species-specific peroxidase anti-peroxidase antibody (ICN, Costa Mesa, CA). Antibodies were localized using 3-3'-diaminobenzidine as a chromogen (Dako Corp, Carpinteria, $\mathrm{CA}$ ). In some cases, antigen retrieval using Biocare Medical decloaking chamber was applied before the incubation of the primary antibody.

\section{Results}

The cellular localization of FOXO3a was examined in the hippocampus of LBD, AD/LBD, and age-matched control patients by immunohistochemical techniques using an antibody to FOXO3a. Whereas immunoreactivity of FOXO3a localized to the cytoplasm similarly in hippocampal neurons in control cases (Fig. 1A) as well as in cases of LBD (Fig. 1B), FOXO3a strongly and specifically localized to cortical Lewy bodies in all cases of pure LBD (Fig. $1 \mathrm{C}$ ) and AD/LBD (Fig. 1D, case of age 64). Lewy neurites also contained FOXO3a in LBD and AD/LBD (Fig. 1E). Immunostaining these same cases for 14-3-3 protein also revealed specific localization in cortical Lewy bodies (Fig. $1 \mathrm{~F}$, case of age 59 ).

The significant overlap between the immunoreactivity to $\alpha$-synuclein and FOXO3a further confirms the specific localization of FOXO3a in cortical Lewy bodies as well as in classical Lewy bodies in the brainstem of cases with PD (Fig. 2). Most Lewy bodies were found to be positive for $\alpha$-synuclein and FOXO3a on adjacent serial sections, indicating the presence of FOXO3a in Lewy bodies in PD brain.

\section{Discussion}

The localization of FOXO3a to Lewy bodies and Lewy neurites in PD and LBD indicates that FOXO3a is a potential component of Lewy bodies. While Lewy bodies are known also to be comprised of $\alpha$-synuclein and ubiquitin $[21]$ and occur in a variety of clinical disease states [7,22- 


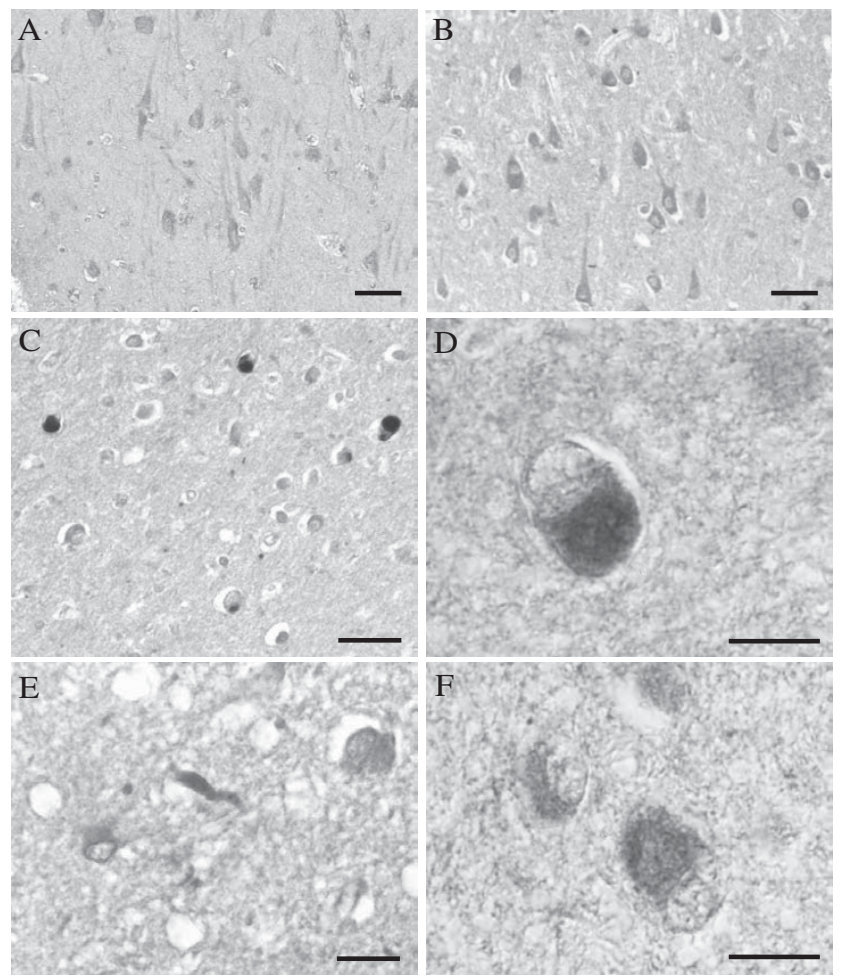

Figure I

In hippocampal neurons, FOXO3a is present at similar levels in control (A), and cases diagnosed with LBD (B). Cortical Lewy bodies, however, exhibit intense immunolabeling for $\mathrm{FOXO} 3 \mathrm{a}$, in cortical regions from all cases diagnosed with pure LBD (C), and with AD/LBD (D). Lewy neurites also accumulate FOXO3a (E). Significantly, cortical Lewy bodies also demonstrate increased I4-3-3 (F). Scale bars $=50 \mu \mathrm{m}(\mathrm{A}-\mathrm{C}) ; 20 \mu \mathrm{m}(\mathrm{D}-\mathrm{F})$.

$24]$, the mechanism of $\alpha$-synuclein accumulation in the Lewy body and its role in disease is poorly understood [7]. The finding of FOXO3a in intimate association with PD/ LBD lesions suggests that LB and Lewy neurite formation
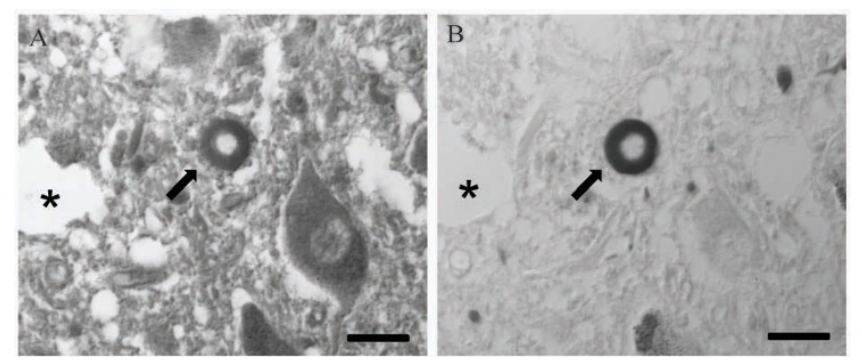

Figure 2

Adjacent serial sections of brainstem of a case of PD immunostained for FOXO3a (A) and $\alpha$-synuclein (B). Co-localization of FOXO3a and $\alpha$-synuclein in classical Lewy bodies (arrows) was observed. *Landmark vessel. Scale bars $=20 \mu \mathrm{m}$. encompasses more basic cellular pathophysiology than simple "gain of function" toxicity. Given the role of FOXO in such processes as phosphorylation, acetylation/ deacetylation, ubiquitination, and protein-protein interactions [25], the potential of multiple hits cannot be discounted [26,27]. In fact, FOXO3a has been shown to trigger the death of motoneurons in mice with the translocation from cytoplasm to nucleus [28], and a recent study also showed oxidative stress induces neuronal necrosis by activating FOXO3 [29].

Interestingly, however, several lines of evidence now indicate that $\alpha$-synuclein accumulation is fundamentally protective [30,31]. In our own studies, $\alpha$-synuclein aggregation occurs in concert with microtubule polymerization and that an aggregate, once formed, is cytoprotective response against noxious stimuli [32,33]. This is compatible with the once controversial concept that neurodegenerative disease lesions are markers of pathogenic disease response rather than indicators of etiology [34,35]

Oxidative stress is believed to be an important factor in cell death induction and considerable evidence has accumulated that oxidative stress is involved in the pathogenesis of PD and $\alpha$-synuclein aggregation [36-38]. As a transcription factor, it is necessary for FOXO3a to locate in nucleus to play its cell death-inducing role. In the present study, the high level expression of FOXO3a protein in an inclusion body in the neuronal cytoplasm suggests that FOXO3a may not reach the nucleus (e.g., to affect its known function in the apoptotic pathway). This finding adds further evidence to the notion that Lewy bodies may protect affected neurons from death and furthers the notion that profound alterations in cytoplasmic-nuclear trafficking are a key element of the neurodegenerative process $[39,40]$. The finding of the specific isoform FOXO3a in neurodegenerative disease as presented in this work, as well as its role in attenuating amyloid-like pathology in mouse models [41], clearly supports the investigation of the other members of the FOXO family transcription factor in aging and disease.

14-3-3 is a family of dimeric proteins that can modulate interaction between proteins and they are involved in cell signaling, regulation of cell cycle progression, intracellular trafficking/targeting, cytoskeletal structure and transcription [42,43]. In previous studies, phosphorylated FOXO3a has been shown to bind to $14-3-3$ protein, causing cytoplasmic retention of phosphorylated FOXO3 and inhibition of FOXO3-induced transcriptional activation [16]. Interestingly, 14-3-3 protein has also been localized to Lewy bodies [8]. Therefore, while the mechanism of accumulation of FOXO3a in Lewy bodies awaits further study, a direct interaction between FOXO3a and 14-3-3 protein remains a distinct possibility. Since $\alpha$-synuclein 
shares physical and functional homology with 14-3-3 proteins [44], it is reasonable to speculate that FOXO3a, $\alpha$ synuclein, and 14-3-3 protein may form a complex, preventing the dephosphorylation and translocation of FOXO3a, and promote cell survival. This potential protein interaction is the subject of ongoing studies in our laboratory.

\section{Conclusion}

Our study demonstrates the localization of FOXO3a protein to Lewy bodies and Lewy neurites, suggesting a role of FOXO3a in the morphogenesis of inclusions in synucleinopathies. Given the pleiotrophic effects of FOXO3a in cellular pathophysiology, our results further the increasingly important concept that inclusion formation is a complex process, favoring an adaptive disease response over a primary deleterious process. Further studies investigating direct protein interaction in vitro and in vivo are in progress.

\section{Abbreviations}

(AD): Alzheimer's disease; (FOXO): forkhead box transcription factor, class O; (LBD): Lewy body dementia; (PD): Parkinson's disease; (TBS): Tris-buffered saline.

\section{Competing interests}

The authors declare that they have no competing interests.

\section{Authors' contributions}

HL, SLS, RC, and BS carried out the experiments. XWZ, RJC, MAS and HGL designed the study, analyzed data, and wrote the manuscript. SGC, XW, EK, AT, and GP participated in the design of the study and helped analyze the data. All authors read and approved the final manuscript.

\section{Acknowledgements}

Work in the authors' laboratories is supported by the National Institutes of Health (AG024028, AG03 I364) and the American Parkinson's Disease Association.

\section{References}

I. Robinson PA: Protein stability and aggregation in Parkinson's disease. Biochem / 2008, 4 I3:1-13.

2. Tofaris GK, Spillantini MG: Alpha-synuclein dysfunction in Lewy body diseases. Mov Disord 2005, 20(Suppl I 2):S37-44.

3. Ross CA, Poirier MA: Protein aggregation and neurodegenerative disease. Nat Med 2004, I0(Suppl):SI0-17.

4. Spillantini MG, Goedert M: The alpha-synucleinopathies: Parkinson's disease, dementia with Lewy bodies, and multiple system atrophy. Ann N Y Acad Sci 2000, 920:16-27.

5. Braak H, Del Tredici K, Rub U, de Vos RA, Jansen Steur EN, Braak E: Staging of brain pathology related to sporadic Parkinson's disease. Neurobiol Aging 2003, 24:197-2II.

6. Spillantini MG, Schmidt ML, Lee VM, Trojanowski JQ, Jakes R, Goedert M: Alpha-synuclein in Lewy bodies. Nature 1997, 388:839-840.

7. Shults CW: Lewy bodies. Proc Natl Acad Sci USA 2006, I03:|66|-1668.

8. Kawamoto Y, Akiguchi I, Nakamura S, Honjyo Y, Shibasaki H, Budka $\mathrm{H}$ : 14-3-3 proteins in Lewy bodies in Parkinson disease and diffuse Lewy body disease brains. J Neuropathol Exp Neurol 2002, 6 I:245-253.

9. Ubl A, Berg D, Holzmann C, Kruger R, Berger K, Arzberger T, Bornemann A, Riess O: I4-3-3 protein is a component of Lewy bodies in Parkinson's disease-mutation analysis and association studies of 14-3-3 eta. Brain Res Mol Brain Res 2002, I 08:33-39.

10. Wakabayashi K, Tanji K, Mori F, Takahashi H: The Lewy body in Parkinson's disease: molecules implicated in the formation and degradation of alpha-synuclein aggregates. Neuropathology 2007, 27:494-506.

II. Foley P, Riederer P: Influence of neurotoxins and oxidative stress on the onset and progression of Parkinson's disease. J Neurol 2000, 247(Suppl 2):II82-94.

12. Castellani RJ, Siedlak SL, Perry G, Smith MA: Sequestration of iron by Lewy bodies in Parkinson's disease. Acta Neuropathol 2000, I00:I|I-I|4.

13. Lin K, Dorman JB, Rodan A, Kenyon C: daf-I 6: An HNF-3/forkhead family member that can function to double the lifespan of Caenorhabditis elegans. Science 1997, 278:1319-1322.

14. Fukunaga $\mathrm{K}$, Ishigami $\mathrm{T}$, Kawano $\mathrm{T}$ : Transcriptional regulation of neuronal genes and its effect on neural functions: expression and function of forkhead transcription factors in neurons. J Pharmacol Sci 2005, 98:205-2II.

15. Burgering BM: A brief introduction to FOXOlogy. Oncogene 2008, 27:2258-2262.

16. Brunet A, Bonni A, Zigmond MJ, Lin MZ, Juo P, Hu LS, Anderson MJ, Arden KC, Blenis J, Greenberg ME: Akt promotes cell survival by phosphorylating and inhibiting a Forkhead transcription factor. Cell 1999, 96:857-868.

17. Tothova Z, Kollipara R, Huntly BJ, Lee BH, Castrillon DH, Cullen DE, McDowell EP, Lazo-Kallanian S, Williams IR, Sears C, Armstrong SA, Passegue E, DePinho RA, Gilliland DG: FoxOs are critical mediators of hematopoietic stem cell resistance to physiologic oxidative stress. Cell 2007, I 28:325-339.

18. Lee HG, Ogawa O, Zhu X, O'Neill MJ, Petersen RB, Castellani RJ, Ghanbari H, Perry G, Smith MA: Aberrant expression of metabotropic glutamate receptor 2 in the vulnerable neurons of Alzheimer's disease. Acta Neuropathol 2004, I 07:365-37I.

19. Smith MA, Kutty RK, Richey PL, Yan SD, Stern D, Chader GJ, Wiggert $B$, Petersen RB, Perry G: Heme oxygenase- $I$ is associated with the neurofibrillary pathology of Alzheimer's disease. Am J Pathol 1994, 145:42-47.

20. Jin GS, Kondo E, Miyake T, Shibata M, Takashima T, Liu YX, Hayashi $\mathrm{K}$, Akagi T, Yoshino T: Expression and intracellular localization of FKHRLI in mammary gland neoplasms. Acta Med Okayama 2004, 58: 197-205.

21. Gai WP, Yuan HX, Li XQ, Power JT, Blumbergs PC, Jensen PH: In situ and in vitro study of colocalization and segregation of alpha-synuclein, ubiquitin, and lipids in Lewy bodies. Exp Neurol 2000, I 66:324-333.

22. Gibb WR, Esiri MM, Lees AJ: Clinical and pathological features of diffuse cortical Lewy body disease (Lewy body dementia). Brain 1987, I I0(Pt 5): I|31-1 I53.

23. Hansen L, Salmon D, Galasko D, Masliah E, Katzman R, DeTeresa R, Thal L, Pay MM, Hofstetter R, Klauber M, et al:: The Lewy body variant of Alzheimer's disease: a clinical and pathologic entity. Neurology 1990, 40: I-8.

24. Lippa CF, Schmidt ML, Lee VM, Trojanowski JQ: Antibodies to alpha-synuclein detect Lewy bodies in many Down's syndrome brains with Alzheimer's disease. Ann Neurol 1999, 45:353-357.

25. Fu Z, Tindall DJ: FOXOs, cancer and regulation of apoptosis. Oncogene 2008, 27:2312-2319.

26. Zhu X, Castellani RJ, Takeda A, Nunomura A, Atwood CS, Perry G, Smith MA: Differential activation of neuronal ERK, JNK/SAPK and p38 in Alzheimer disease: the 'two hit' hypothesis. Mech Ageing Dev 200I, I 23:39-46.

27. Zhu X, Raina AK, Perry G, Smith MA: Alzheimer's disease: the two-hit hypothesis. Lancet Neurol 2004, 3:219-226.

28. Barthelemy C, Henderson CE, Pettmann B: Foxo3a induces motoneuron death through the Fas pathway in cooperation with JNK. BMC Neurosci 2004, 5:48.

29. Davila $D$, Torres-Aleman I: Neuronal death by oxidative stress involves activation of FOXO3 through a two-arm pathway that activates stress kinases and attenuates insulin-like growth factor I signaling. Mol Biol Cell 2008, I 9:20 I4-2025. 
30. Hashimoto M, Hsu LJ, Rockenstein E, Takenouchi T, Mallory M, Masliah E: alpha-Synuclein protects against oxidative stress via inactivation of the c-Jun $\mathrm{N}$-terminal kinase stress-signaling pathway in neuronal cells. J Biol Chem 2002, 277: I 1465-II472.

31. Manning-Bog AB, McCormack AL, Purisai MG, Bolin LM, Di Monte DA: Alpha-synuclein overexpression protects against paraquat-induced neurodegeneration. I Neurosci 2003, 23:3095-3099.

32. Hasegawa T, Matsuzaki M, Takeda A, Kikuchi A, Akita H, Perry G, Smith MA, Itoyama $Y$ : Accelerated alpha-synuclein aggregation after differentiation of SH-SY5Y neuroblastoma cells. Brain Res 2004, 1013:51-59.

33. Matsuzaki M, Hasegawa $T$, Takeda A, Kikuchi A, Furukawa $K$, Kato $Y$, Itoyama $Y$ : Histochemical features of stress-induced aggregates in alpha-synuclein overexpressing cells. Brain Res 2004, 1004:83-90.

34. Castellani RJ, Lee HG, Zhu X, Nunomura A, Perry G, Smith MA: Neuropathology of Alzheimer disease: pathognomonic but not pathogenic. Acta Neuropathol 2006, I I I:503-509.

35. Castellani RJ, Lee HG, Zhu X, Perry G, Smith MA: Alzheimer disease pathology as a host response. I Neuropathol Exp Neurol 2008, 67:523-531.

36. Giasson BI, Duda JE, Murray IV, Chen Q, Souza JM, Hurtig HI, Ischiropoulos $H$, Trojanowski JQ, Lee VM: Oxidative damage linked to neurodegeneration by selective alpha-synuclein nitration in synucleinopathy lesions. Science 2000, 290:985-989.

37. Sayre LM, Perry G, Smith MA: Oxidative stress and neurotoxicity. Chem Res Toxicol 2008, 21:172-188.

38. Castellani RJ, Perry G, Siedlak SL, Nunomura A, Shimohama S, Zhang J, Montine T, Sayre LM, Smith MA: Hydroxynonenal adducts indicate a role for lipid peroxidation in neocortical and brainstem Lewy bodies in humans. Neurosci Lett 2002, 319:25-28.

39. Lee HG, Ueda M, Miyamoto Y, Yoneda Y, Perry G, Smith MA, Zhu X: Aberrant localization of importin alphal in hippocampal neurons in Alzheimer disease. Brain Res 2006, I I 24: I-4.

40. Lee HG, Ueda M, Zhu X, Perry G, Smith MA: Ectopic expression of phospho-Smad2 in Alzheimer's disease: uncoupling of the transforming growth factor-beta pathway? J Neurosci Res 2006, 84: $|856-| 86 \mid$.

4I. Qin W, Zhao W, Ho L, Wang J, Walsh K, Gandy S, Pasinetti GM: Regulation of forkhead transcription factor FoxO3a contributes to calorie restriction-induced prevention of Alzheimer's disease-type amyloid neuropathology and spatial memory deterioration. Ann N Y Acad Sci 2008, II 47:335-347.

42. Aitken A: 14-3-3 proteins: a historic overview. Semin Cancer Biol 2006, 16:162-172.

43. Castellani RJ, Honda K, Zhu X, Cash AD, Nunomura A, Perry G, Smith MA: Contribution of redox-active iron and copper to oxidative damage in Alzheimer disease. Ageing Res Rev 2004, 3:319-326.

44. Ostrerova N, Petrucelli L, Farrer M, Mehta N, Choi P, Hardy J, Wolozin B: alpha-Synuclein shares physical and functional homology with 14-3-3 proteins. J Neurosci 1999, 19:5782-5791.

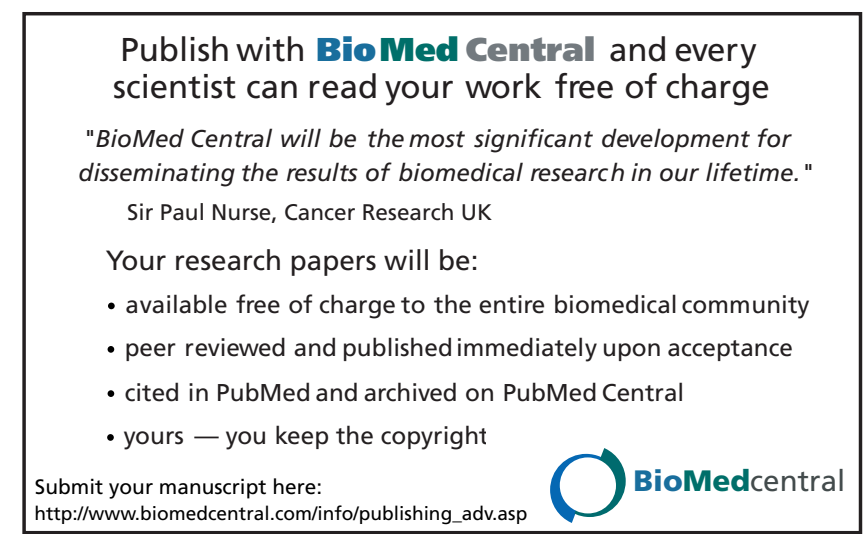

